\title{
Autorretrato das narrativas de mulheres docentes: poesias de desenhos pessoais e profissionais
}

\author{
Paula Lemos Silveiral e Vaneza Silva da Rosa ${ }^{2}$ \\ doi.org/10.47585/nemtudosaorosas 10
}




\section{Introdução}

Para compreendermos as nossas narrativas de vida, faz-se necessário nos apresentarmos e nesse sentido optamos por sermos identificadas por um dos nossos sobrenomes: A Silveira e A Rosa. Justificamos as escolhas, pois cada sobrenome traz consigo narrativas afetivas, experiências que nos tocam em nossas diferenças. Ecos de vozes em nossas memórias, ou que permanecem silenciadas com o tempo. Recordações que nos permitem olhares analíticos para nós mesmos.

Inspiradas pelas palavras de Mário Quintana, analisamos que o poeta constrói a poesia em distintos atos: $\mathrm{O}$ de criação da obra e o de se construir enquanto pessoa. $\mathrm{O}$ título do poema mostra a necessidade do Poeta em se auto-retratar para o outro, segundo Quintana (2021):

"No retrato que me faço - traço a traço - ...

às vezes me pinto nuvem, às vezes me pinto árvore...

às vezes me pinto coisas de que nem há mais lembrança..

ou coisas que não existem mas que um dia existirão...

e, desta lida, em que busco - pouco a pouco - minha eterna semelhança,

no final, que restará? Um desenho de criança...

Terminado por um louco!"

(QUINTANA, 2021, p.1).

Sendo assim, fomos provocadas por nossas narrativas marcadas por muitos retratos que se constituem em autorretratos nos quais, inventamos cores, traços, linhas, palavras, sentido singular mas também plural pois, cada uma de nós traz consigo as relações que nos afetaram e afetam em nossos percursos existenciais. Por isso, somos vozes de muitas outras vozes, somos professoras porque de alguma maneira tivemos professores que nos deixaram a sua presença com: conhecimentos, afetos, insegurança, receptividade, alegria, em outros aspectos que foram sentidos em nossas experiências escolares, acadêmicas e pessoais.
Desta forma, temos o objetivo de compreender como as nossas narrativas de vidas pessoais e profissionais respondem aos nossos modos de ser pessoa e docente. A problemática que nos movimenta se apresenta na seguinte questão: Como as narrativas de vida pessoais e profissionais respondem aos nossos modos de ser na pessoalidade e profissão?

Desenhamos os nossos autorretratos, traço a traço, alinhavados numa colcha de retalhos. Tais alinhavos, movimentam-se em suas linhas, pontos, não permanecendo em um único lugar. Em cada alinhavo um novo começo, algo desconhecido que poderá ser sentido nas relações com os outros.

Dito isso, é relevante mencionar que nas narrativas das nossas experiências pessoais e profissionais, em algum acontecimento que, na vida fomos interpeladas, iremos nos encontrar. Não porque escolhemos este encontro, mas fomos escolhidas por ele. E a partir dele os nossos vínculos afetivos se transformaram em relações de amizade, pois para cada uma de nós, os nossos percursos de vida se desenham em:

[...] encontros e desencontros, [...]. Alguns desses encontros, poucos, talvez, possam ter sido escolhidos por mim [...] Outros, certamente me encontraram e por eles fui escolhida. Sou feita por uns e por outros a tal ponto que não consigo mais distingui-los [...]. (GARCIA, 2018, p. 163).

E a partir desses, um autorretrato de si mesmo que deixou-se ser afetado por pluralidades, tornando-se quem sabe, um outro desejado, talvez uma reinvenção de si, trazendo descritos em seus desenhos narrados a permissão de novos olhares que nos permitem a escuta de nossas próprias vozes. Um desfazer do que está em nós, sendo refeito para outro recomeçar.

As imagens narradas como uma fotografia serão um artefato que produz algo, capta gestos, retratando movimentos que geram memórias eternizadas em uma imagem, podemos também produzir nossa auto imagem artística, nos autorretratando através de nossa própria selfie nos identificando apenas por uma pose tais análises nos levam a pensar na identidade dos estudos culturais que segundo 
o autor Hall (2006, p.8), identidades culturais trazem aqueles aspectos de nossas identidades que surgem de nosso "pertencimento" a culturas étnicas, raciais, lingüísticas, religiosas e, acima de tudo, nacionais e pode-se dizer que o autorretrato se configura como uma maneira de representação da própria identidade do incluído.

Ao iniciar o nosso desenho, pensamos aqui na docência como uma ampla temática, que se entrelaça às nossas autorias nas narrativas de vida. Sendo assim, a pesquisa qualitativa proporciona um modelo de entendimento profundo de ligações entre elementos, direcionado à compreensão da manifestação do objeto de estudo (MINAYO, 2007). Assim, a abordagem qualitativa aplica-se ao estudo, das relações, das representações, das crenças, das percepções e das opiniões, produto das interpretações que os seres humanos fazem, de como vivem, constroem seus artefatos através de si mesmos, sentem e pensam (TURATO et al, 2008). Cada uma, com seus retalhos moldaram essa colcha, justamente porque lança aos nossos sentimentos o que somos, algo que nos une e nos constitui como humanos.

Baseados em nossas experiências de tudo aquilo que nos toca, nos passa, nos desafia, nos movimenta enquanto seres docentes. Assim, buscamos:

[...] à docência como um lugar privilegiado de experimentação, de transformação de si, de exercício genealógico-lugar de indagação sobre de que modo nos fizemos desta e não daquela forma, de que modo temos recusado ser isto ou aquilo, no caso, como docentes. (FISCHER, 2009, p.94).

Com isso estamos assumindo a nossa docência como desenhos entre diferentes traços, nesses desenhos, em que somos as artisteiras de nossas vidas, vamos percorrendo cada traço ao desconhecido na medida em que as nossas histórias estejam sendo narradas.

Muito mais que um conjunto de técnicas de pesquisa, as nossas trajetórias de vida representam então uma perspectiva colocada frente à construção do conhecimento social. Uma abordagem como esta visa reconhecer as inúmeras facetas deste processo construtivo / narrativo que denominamos em geral por ciência, indistintamente do campo ou área do conhecimento a que possa ser aplicada. A construção de trajetórias de vidas envolve também a compreensão da nossa relação enquanto mulheres corpo e sociedade, de nossas fases da vida tendo como foco analítico as experiências docentes que se entrelaçam. Experiências aqui pensadas a partir dos estudos de Larrosa (2020).

Ter experiência em algo é, antes de tudo, estar imerso em eventos ou ações [...] que trazem consigo suas próprias lições, seu próprio aprendizado, seu próprio conhecimento [...], e é uma condição da experiência estar envolvido em fazer, em uma prática imersa no mundo que nos chega, que nos implica, que nos compromete ou, às vezes, que exige ou nos impõe. (LARROSA, 2020, p. 1).

Então, fomos interpeladas por esta analogia dos desenhos como autorretratos de vidas, possibilidades na construção do conhecimento social em contextos contemporâneos frente a importância da mulher e de sua trajetória que para Larrosa (2020, p.3) "são experiências que envolvem o corpo que é o lugar onde cada história singular é inscrita", o lugar, onde sentimentos e pensamentos se manifestam em batimentos cardíacos, em palavras, em imagens.

Buscamos nos desenhos, nossa própria identidade enquanto mulheres, que movimentam-se em seus emaranhado de fios, costurando uma colcha de retalhos. Entrelaçamos e inventamos nossos tons, traços, espaços, modos de existências na pessoalidade e profissionalização. Os autorretratos que os percursos da vida nos fazem pintar e narrar, nos permitindo diferentes modos de sentir e olhar para nós mesmos.

Neste sentido, as nossas narrativas irão produzir relações com cada uma de nós, de modo singular e também plural, como já foi dito anteriormente, sinalizando desta maneira possibilidades para compreendermos as dimensões do pessoal e profissional no ser professora. Assumindo a nossa autoria nesta escrita não como:

[...] domínio, mas de compromisso, que não seja de apropriação, mas de transformação. Que exista alguém dentro de nossa forma de escrever, de nossa forma de pensar, de nossa forma de viver. Seja o que for. Que mantenhamos, ao menos, a mínima dignidade de escrever sem mentir e sem mentir para nós, num presente cada vez mais difícil e nunca garantido. Numa primeira pessoa cada vez mais impossível, mas sempre perseguida. Numa distância crítica cada vez mais 
problemática e mais cética, mas cada vez mais livre. Ao mesmo tempo no singular e no plural. Escrevendo. Pensando. Vivendo. Sempre no devir. (LARROSA, 2004, p. 42).

Portanto, nossos desenhos são experiências de diferentes invenções: mulher, mãe, dona de casa, professores e administradoras de nossas vidas em constantes transformações de carreira, estudos, trabalhando em nossas instituições de ensino. Como olhares distintos para a construção de nossa existência enquanto obra de vida, onde o autor, personagem e narrador como diz Larrosa(2011) se unificam na pessoa. na E nesta analogia de desenhos em retalhos iremos tecer os nossos autorretratos, as palavras irão contornar as imagens, lugares, cheiros, pessoas, fatos, vozes e até mesmo o silenciamento, como experiências sentidas na relação consigo mesmo ao encontro de outros num compromisso ético, político e social.

\section{O Autorretrato da Silveira}

Ao escrever meu autorretrato como uma representação, me sinto uma artista, em que a históri está nos inúmeros autorretratos pintados que expressam a luta para permanecer viva, estampada em um desenho, que faz sentir tudo que sou e que talvez faça sentido para alguns leitores. Invento e reinvento o que eu imagino, desejo ou talvez idealize ser. Constitui-se do meu discurso feito na primeira pessoa, como minha, autobiografia visual, em uma revelação de um olhar voltado sobre si mesma, fico reflexiva ao me descrever pensando em quais traços utilizar.

Desconfio que tento encontrar minha identidade em um autorretrato, onde se pintam de várias maneiras, através de palavras rabiscadas em meu imaginário, por onde vagam as lembranças passadas, para que venham ter importância, contribuindo para o momento, até mesmo sonhos que ainda não foram, mas que ainda serão realizados, escrevo com as tintas fazendo rabiscos, que talvez só faça sentido para minha pessoa que escolhe a tinta com amor de artesã, cabendo a cada leitor compreender conforme a sua interpretação o desenho pintado através dessas singelas palavras, que segundo o autor:

As palavras determinam nosso pensamento porque não pensamos com pensamentos, mas com palavras, não pensamos a partir de uma suposta genialidade ou inteligência, mas a partir de nossas palavras. E pensar não é somente "raciocinar" ou "calcular" ou "argumentar", como nos tem sido ensinado algumas vezes, mas é sobretudo dar sentido ao que somos e ao que nos acontece. (LARROSA, 2002, p.2).

Ao trazer minhas primeiras reflexões através das palavras, faço uma luta entre elas, sendo essa uma luta em vão, pois pinto as letras de um poema, como uma música, em que me pergunto quem sou? Sou a Silveira, nasci na região da campanha, no estado do Rio Grande do Sul, mulher, filha de marceneiro, um artista e de uma mãe dona de casa, batalhadora, vida simples, sem pompas, mas graças aos meus pais recebi uma educação rica em caráter e valores.

Em versos componho uma flor, essa flor se alterna em cor, entre um bloco, uma caneta desenho minha familia com muito amor que ao iniciar minha vida fui presenteada com quatro irmãs, que são minhas próprias vidas vivenciando uma infância maravilhosa, sendo eu a segunda mais velha, seguindo os passos dos meus pais, que me ensinaram trabalhar mas estudar como foco principal, pois ambos, tinham muita preocupação com o futuro das maninhas, mulheres, inseridas em uma sociedade não tão feminista.

Morando em um mundo totalmente desenhado, colorido, moldo minha escrita em que me pergunto: Quem sou hoje? Docente, casada com o Maneco, vindo de um primeiro casamento, constituímos uma família não tanto tradicional mas pautada no amor, tenho um filho que é meu enteado, pois a minha natureza não me permitiu ser mãe, mas também, sou mãe de um cachorro, sendo assim, aqui esboço meu primeiro desenho, como um retalho que me constitui desde minhas primeiras instituições ou relações sociais. Em meio a minha família, compreendi a escrita das palavras amor, respeito, vida, gratidão e acolhimento.

Nesse desenho, penso ser importante traçar aqui nesse esboço, algo que que me constitui, que é minha formação para que possa tornar-se visível e inspirar a outros. Assim, passo a rabiscar meus primeiros 
traços que teve início, sem eu perceber, em um curso no SENAC, de informática. Nos anos 80 surgiram os primeiros microcomputadores, logo em seguida, me ofereceram vaga no setor de tecnologia de uma loja, fiz um teste, fui selecionada, trabalhando com digitação, logo em seguida operação fazendo algumas rotinas de backup, trabalhei com diferentes sistemas, de cadastro, notas, crediário.

A empresa de consultoria que desenvolvia os sistemas para loja, me convidou para trabalhar com consultoria de software, o dono da empresa era professor em uma universidade, eu havia iniciado minha faculdade em Ciências Contábeis e influenciada por ele passei para o curso de Informática, me formei bacharel em Informática, com esse mesmo chefe, que foi meu professor orientador e ao mesmo tempo, um mês antes de minha defesa sofreu um grave acidente e veio a falecer. No meu trabalho final eu mantive o seu nome como meu orientador, sendo esse meu segundo desenho traçando meu início profissional e universitário.

Esse mesmo professor, chefe, orientador, antes do seu falecimento, solicitou que preenchesse uma ficha em uma escola de cursos em que ele era diretor, eu estava concluindo um curso de hardware, logo que me formei, fui chamada, por outro diretor que assumiu o lugar do meu antigo chefe. Iniciei as atividades dando manutenção em equipamentos.

Nessa escola assistia as professoras em sala de aula pois a escola era toda com divisórias de vidro, uma proposta muito moderna e interessante. Eles atendiam crianças de escolas conveniadas de todas as séries e níveis escolares até adultos. Em um dos dias de trabalho uma das professoras faltou e pediram para que eu ficasse com as crianças, foi um amor à primeira vista, houve um encantamento.

Passei a trabalhar com as crianças e logo em seguida percebi que os alunos mais jovens me chamavam para que eu auxiliasse, perdi o medo e passei a trabalhar com todas as idades, em diferentes cursos, na área de informática, essa escola era vinculada a uma universidade e a administração resolveu fechar a escola, entregando o prédio, então fomos para uma sala da universidade, fui para uma sala do curso técnico em Informática da universidade na qual fiz uma seleção e ingressei desde o ano de 2000.

Procurando compreender a minha constituição identitária como profissional então docente a partir das vivências pessoais mescladas às experiências formativas compreendidas desde a inserção nesse universo formativo, em que Tardif (2008), cita que os ingressantes na docência, além dos aprendizados adquiridos na formação, carrega consigo saberes das experiências de sua vida estudantil como respaldo, fazendo articulações entre o tempo e aprendizagem do trabalho docente que se diferenciam das outras profissões.

Sendo assim o professor passa por diversos aprendizados em sua formação sendo afetados por diferentes saberes da experiência que os constituem. que segundo Larrosa (2000):

Se a experiência é o que nos acontece e se o saber da experiência tem a ver com a elaboração do sentido ou do sem-sentido do que nos acontece, trata-se de um saber finito, ligado à existência de um indivíduo ou de uma comunidade humana particular; ou, de um modo ainda mais explícito, tratase de um saber que revela ao homem concreto e singular, entendido individual ou coletivamente, $o$ sentido ou o sem-sentido de sua própria existência, de sua própria finitude. (LARROSA, 2002, p.8).

Então em 2002 passo a ser docente, tratando daquilo que me constitui como ser docente, ao mesmo tempo que movimenta concepções, balança certezas. São grandes os desafios diários de quem trabalha em uma das instituições de ensino superior comunitárias, sendo uma na Região da Campanha no Rio Grande do Sul. Essa instituição é minha segurança em um lindo desenho que redesenho. Pintura em quadro de uma universidade que desenvolve seu papel pautada em causas sociais, mantém várias ações voltadas para comunidade, temos um hospital universitário que atende a comunidade carente diariamente, demonstrando responsabilidade social.

Nesse autorretrato que estou inventando ser, a artista que estuda e trabalha com as tecnologias se mostra apaixonada por espaços virtuais pois estes também são espaços de conhecimento. Sendo essas as primeiras rabiscos iniciais como docente no ensino superior, houve a necessidade de planejamento, como docente da graduação, em uma disciplina de Educação e Tecnologia, conduzindo uma turma de alunos, estudantes de Pedagogia que coloriram minha vida, como diz Larossa (2002, p. 8) o saber da experiência é um saber particular, subjetivo, relativo, contingente, pessoal considerando que em minha vida surgiram novos desafios, em 2002 conclui especialização em educação, me ofereceram o cargo 
de Coordenadora do Curso Técnico em Informática, de 2003 até 2012. Concomitantemente, entre os anos de 2009 a 2017, trabalhei como administradora em Ambientes Virtuais de Aprendizagem, os quais eram utilizados como apoio às disciplinas presenciais.

Em 2016, fui aprovada para cursar Mestrado em Educação, na Universidade de Santa Cruz do Sul (UNISC), dando início aos primeiros passos desenhados como uma talvez, possível pesquisadora e escritora.

Já em 2019, ingressei no doutorado, passei por problemas de saúde, mas recuperada dei continuidade aos meus estudos que no momento penso ser importante sempre estudar para visualizar esses novos modos de modos de ser docente, diante da transformação digital e das crescentes demandas do trabalho docente.

Dessa maneira, visualizo as oportunidades que me são dadas como uma possibilidades de ( $\mathrm{r}$ ) desenhar, os novos modos de ser docente com o envolvimento das tecnologias. Necessitando novos olhares, procurando perspectivas ou combinações possíveis para as articulações conceituais que geram estranhamento que aqui se justifica para essa vontade de saber, de atualizar-se, que talvez seja um entrelace entre as experiências pessoais e acadêmicas que para o autor Larrosa:

A experiência é o que nos passa, o que nos acontece, o que nos toca. Não o que se passa, não o que acontece, ou o que toca. A cada dia se passam muitas coisas, porém, ao mesmo tempo quase nada nos acontece. (LARROSA, 2002, p.2).

As reviravoltas metodológicas em sala de aula são resultados das valorizações sociais da atualidade, no que se refere ao conjunto coletivo subvertendo as mentalidades e os valores tradicionais. Neste sentido, talvez seja relevante refletir sobre as mudanças nas ações docentes e como essas poderão repercutir nos modos de ser docente, como uma bússola procurando uma direção, um horizonte.

Uma das tecnologias que nos movimentou foi o advento da Internet rede de comunicação entre milhões de computadores e pessoas conectadas, proporcionam a interação, essas tecnologias chegaram para ficar, não tem volta e contribuem para essa desacomodação no ensino sendo considerado um dos desafios, oportunizando mudanças nas ações docentes devido a socialização em tempo real do conhecimento e acesso imediato de informações.

Dessa maneira, focada na área da Educação, traço minha escrita voltada para as tecnologias digitais, os ambientes virtuais, tecnologias móveis em grande expansão e a atual valorização da Modalidades educacionais em diferentes espaços são modelos que nos proporcionam novas experiências tanto para o docente como para o discente ainda mudando a maneira de como nos relacionamos, nos comunicamos e que ainda poderão gerar grandes mudanças em todos os aspectos relacionados a nossa vida, que aqui admito ser uma questão inquietante, pois proporcionam criação, reinvenção e inovação em que os docentes em constante transformação.

Trago em meu autorretrato que é uma forma de pintura, que demonstra a noção do meu ser, como em um modelo retratado, de minha autoria em que sou a própria artista em vários redesenhos, ao longo dos últimos 21 anos de carreira como docente, traçando minha auto performance, uma trajetória de luta, que me dispus a criar, considerando que é minoria das mulheres que possuem formação nas áreas das tecnologias, que aqui nesse espaço, desenho, redesenho, unindo, reunindo meus processos criativos, sempre imaginando as possibilidades que as tecnologias proporcionam, na sua abrangência, disponibilidade no mundo virtual em que presencialidade é substituída por acessos, de que também reinventam transformando-se em novos desenhos de escrita, da comunicação, capazes de diminuir distâncias, ampliar conhecimento.Enfim, nesse momento em que coloco um ponto final em minhas narrativas, convido a Rosa para desenhar o seu autorretrato.

\section{Autorretrato da Rosa}

Nos meus desenhos em suas formas indefinidas deixados nos pedaços de retalhos por alguém que me afeta, sigo em meus rabiscos, traçando a beleza da minha arte, não somente em sua 
exterioridade, mas também, nas relações que a constituem. O meu autorretrato está nos movimentos da vida, com diferentes tonalidades, nas linhas que são onduladas, às vezes curvas outras retas. Sigo inventando o meu ser mulher, mãe, professora e pesquisadora. A minha história de vida começa em uma cidade localizada na região central do Rio Grande do Sul- Santa Maria da Boca do monte, caracterizada por seu vento norte.Ventos que movimentam os meus pensamentos, me fazendo recordar da minha mãe, narrando os fatos que antecederam o meu nascimento. Na gestualidade do seu corpo, olhares e palavras, os acontecimentos eram narrados. E, com eles entendi que para nascer foi necessário as linhas de fuga, para eu resistir às negações do meu pai motivadas pela ausência de recursos financeiros e também pela falta de uma relação estável de casamento. Entretanto, quando eu nasci, o lugar da negação foi perdendo as suas forças, pois o movimento do amor foi se tornando mais potente, possibilitando diferentes afetos potencializadores das nossas vidas. E tais afetos, também são sentidos no ser professora e pessoa, nas exclusões que perpassam olhares, palavras, silenciamentos, gestos, enfim, o que movimenta as nossas existências.

$\mathrm{Na}$ infância fui desacomodada por experiências familiares de amorosidade, um irmão, descobertas, inquietudes, amizades não quantificadas, brincadeiras comigo mesma, com o meu irmão e com duas amigas que permaneceram comigo nos percursos da vida. O tempo não era marcado pelos movimentos e contagem dos ponteiros de um relógio e sim pela lentidão de um: [...] parar para pensar, parar para olhar, parar para escutar, pensar mais devagar, olhar mais devagar,
e escutar mais devagar; parar para sentir, sentir mais devagar, demorar-se nos detalhes, suspender a
opinião, suspender a vontade, suspender o automatismo da ação, cultivar a atenção e a delicadeza, abrir
os olhos e os ouvidos, falar sobre o que nos acontece, aprender a lentidão, escutar aos outros, cultivar a arte do encontro, calar muito, ter paciência e dar-se tempo e espaço. (LARROSA, 2015, p. 25).

E nos passos dessa lentidão que me tocava seguia os percursos da minha história, em cada retalho um autorretrato, às vezes com diferentes estampas, ou apenas de uma cor, neles fui traçando as minhas rosas, pois sou feita de muitas outras, algumas com espinhos que me machucaram e ainda são doloridos, com outras, algumas das minhas pétalas caíram, no entanto, trago comigo o meu sorriso, assim como está escrito na música de Almir Sater (Tocando em frente) "eu já chorei demais".

Nesses lugares por onde eu andei a minha família foi e continua sendo a âncora que me sustenta: a minha mãe, uma mulher movida por sua espiritualidade, o meu porto seguro, o meu irmão, a pessoa amiga, com quem eu posso confiar. O meu pai é um homem de poucas palavras e sorrisos, mas que sempre me incentivou a estudar. Por algum tempo, a nossa relação foi conflituosa, conflitos motivados pelo uso de álcool- o meu pai por muitos anos foi uma pessoa alcoólatra e agressiva. Todavia, chegou um tempo em que a doença lhe fez parar, possibilitando-lhe um outro começo. E foi assim, que juntos inventamos os nossos afetos para outros desenhos nos retalhos da vida pintar. Por fim, a minha filha, a grande surpresa, o amor em potência que fez desaprender o aprendido, me tornando mãe.

Pois bem, nos ritmos dos meus passos, experienciei lugares, sentimentos, relacionamentos,conhecimentos, modos de ser pessoa em estradas e atalhos. As minhas narrativas são práticas de um cuidado que tenho comigo mesma, por isso me autorizo a contorná-las a partir dos lugares que eu habitei ou que ainda estou habitando. Pois, o cuidar-se de si implica um voltar-se para si mesmo, para haver possibilidades de encontro com o outro. E assim, faz-se "necessário manter as relações de amizade". (FOUCAULT 2004,p. 5)

Desse modo, movimentada por minhas recordações me encontro com o curso de Educação Especial, na Universidade Federal de Santa Maria o qual começou a ter sentido para mim no $4^{\circ}$ semestre, quando comecei a trabalhar como bolsista no projeto intitulado Laboratório de alfabetização: Repensando a formação de professores, fato que me fez aproximar a minha vida acadêmica da profissional. E ao ser interpelada por esse profissional, conclui o curso de graduação em educação especial e nos alinhavos dos retalhos que esse me deixou, na Escola de Educação Especial Recanto da Esperança APAE, DE CHAPECÓ (Santa Catarina) no ano de 2004, reiniciei outro autorretrato, o desenho da professora atuando no cargo de coordenadora pedagógica. Como também, retomei o meu 
percurso acadêmico no curso de Pós-Graduação em Psicopedagogia Institucional na Universidade Regional de Chapecó (UNOCHAPECÓ). Logo após a conclusão do curso, me senti afetada na experiência de ser professora horista nessa instituição.

Todavia, o meu desejo era retornar ao Rio Grande do Sul, e fui traçando linhas para conquistá lo. E assim, cheguei em sua concretização por meio da aprovação e nomeação em um concurso público municipal, no segundo semestre do ano de 2007, para o cargo de professora de educação especial para alunos com o Transtorno do Espectro Autista ${ }^{3}$, em uma cidade do Vale do Rio Pardo, na região Sul do Brasil. Tais experiências recordadas me permitiram sentir os afetos, inventando o meu modo de ser pessoa e professora, sendo "estrangeira num novo território", (ROOS, 2014, p.48).

Por meio dessas invenções fiz possíveis escolhas e uma delas foi a aprovação no curso de Mestrado em Educação, na Universidade de Santa Cruz do Sul (UNISC), no ano de 2016. A professora começou a pintar um autorretrato da pesquisadora.

E também foi nesse curso, o meu encontro com a Silveira, como um ímã nos atraímos, permanecemos juntas, não somente na escrita, na pesquisa, mas na docência enquanto vida. "pensar no tempo vivido por cada uma de nós. Refletir sobre a docência, profissão escolhida e exercida por nós. Colocarmo-nos atentas ao presente e à docência, atendendo a ambos, sendo tocadas e tocando, tanto o presente quanto a docência”. (SILVA;TOMASEL, 2018, p.108).

Nesses encontros em que fomos sendo tocadas, cada uma foi desenhando as suas experiências, pessoais, profissionais e acadêmicas, em algumas situações estivemos juntas, companhias que como diz (Foucault 2014) que provocam fissuras na solidão.

No mestrado eu fui pintando as minhas pétalas nas disciplinas, leituras e escritas, grupos de estudos com professores e colegas, inclusive com a Silveira, se não estivesse na presença física, estava em meus afetos e pensamentos.
Nessas pinturas, eu fui me inventando, busquei expandir território e nessas tentativas de me inventar, cheguei ao término de 2018 com um objetivo concretizado: a aprovação no curso de Doutorado em Educação na Universidade de Santa Cruz do Sul (UNISC), a mesma instituição do mestrado. Entretanto, devo dizer que antes de chegar a essa aprovação, as minhas incertezas e inquietações em continuar seguindo ou não, a vida acadêmica, foram amenizadas pela companhia da minha amiga Silveira, ou seja, o nosso vínculo afetivo me impulsionou a continuar nesse percurso. Uma vez que, os afetos que nos unia eram mais potentes que as minhas incertezas. Sendo agora aluna caminhante em um curso de pós-graduação, no doutorado, estou me permitindo estudar as docências, vidas afetadas por outras vidas, como nessa escrita em que as palavras ditas ou não ditas, são a presença de diferentes autorias que se aproximam para narrar a si mesmo em seus desenhos nos pedaços de retalhos, expressando os seus autorretratos poéticos.

\section{Considerações finais}

Como uma exposição artística em que ao mesmo tempo se vive, se desenha, aqui compomos nossos autoretratos, em nossas performances na qual nós atestamos uma possível veracidade dos fatos, narramos nossas experiências entrelaçadas como pesquisadoras desde o mestrado, colegas também de doutorado, em uma necessidade crescente de pensar, não um pensar porque se quer, mas porque algo, ou alguém, nos faz pensar e assim compomos nossa maneira de ser-no-mundo, tendo alguns encontros e desencontros em nossos caminhos.

Com os nossos desenhos de imagens únicas, as nossas narrativas foram compostas de maneira sutil e aberta, possibilitando interpretações e identificações. Dentro deste contexto, foram analisadas as obras de duas artistas que se permitiram a partir das suas singularidades, expressar

3 Transtorno do Espectro Autista (TEA) - Terminologia usada nos dias atuais e que se refere a déficits na comunicação social e na interação social em múltiplos contextos (AMERICAN PSYCHIATRIC ASSOCIATION, 2014, P.50). 
a pluralidade de linguagens, compondo pessoalidades, formação e profissionalização, como uma sobreposição de imagens em série.

Em nosso emaranhado de fios, traços, pontos, desenhos bordados, nos encontramos em nossas escritas nos identificando como: mulheres, mães, donas de casa, docentes, estudantes, pesquisadoras, pintando nosso autorretrato por traços de amizades de encontros de saberes compartilhados de maneira potente.

Sendo assim, ao desenharmos nosso autorretrato, com as mão livres, agora então pintamos nosso autorretrato em vários traços, trazendo uma única imagem de mãos dadas, redesenhamos nossas maneiras de ser docente procurando atribuir sentidos, identificando nossas marcas pessoais em nossas maneiras de pintar ou desenhar, deixando registros ao anoitecer, em seus alinhavos madrugada a dentro e finalizando ao amanhecer.

\section{Referências}

AMERICAN PSCHIATRIC ASSOCIATION. DSM-V: manual de diagnóstico de transtornos mentais. 5. ed. Porto Alegre: Artmed, 2014.

FOUCAULT, Michel. Ditos e escritos V: Ética, Sexualidade e Política. Tradução de Elisa Monteiro e Inês Dourado Barbosa. 3. ed. Rio de Janeiro: Forense Universitária, 2014.

FOUCAULT, Michel. A ética do cuidado de si como prática de liberdade. In: FOUCAULT, Michel. Ditos \& Escritos V: Ética, Sexualidade, Política. Rio de Janeiro: Forense Universitária, 2004. p. 1-14.

GARCIA, Maria Manuela Alves. Experiências de docência e pesquisa em uma universidade pública. In: FABRIS, Elí T. H.; DAL'IGNA, Maria C.; SILVA, Roberto R.D. (Org.). Modos de ser docente no Brasil contemporâneo: articulações entre pesquisa e formação. São Leopoldo: OIKOS, 2018. p. 161-178.
HALL, Stuart. A identidade cultural na pós-modernidade. Tradução de Tomaz Tadeu da Silva e Guaracira Lopes Louro. 11. ed. Rio de Janeiro: DP\&A, 2006.

LARROSA, Jorge. Notas sobre a experiência e o saber de experiência. Rev. Bras. Educ. n. 19. Rio de Janeiro, jan./abr. 2002

LARROSA, Jorge. A operação ensaio: sobre o ensaiar e o ensaiar-se no pensamento, na escrita e na vida. Revista Educação e Realidade. Porto Alegre, v. 29, n. 1, p. 27-43, jan./jun. 2004.

LARROSA, Jorge. El Professor Artesano. Editora: Noveduc. 2020.

LARROSA, Jorge. Tecnologias do eu e educação. In: SILVA, Tomaz Tadeu (Org.). O sujeito da educação: estudos foucaultianos. Petrópolis, RJ: Vozes, 2011. p. 35-84.

LARROSA, Jorge. Tremores: escritos sobre experiência. Belo horizonte: Autêntica, 2015.

MINAYO, M.C.S. O Desafio do Conhecimento: Pesquisa Qualitativa em Saúde. 10. ed. São Paulo: HUCITEC 2007. $406 \mathrm{p}$

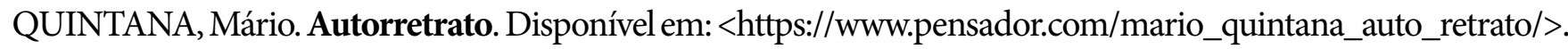
Acesso em: 18 mar. 2021.

TURATO, E. R. et al. Amostragem por saturação em pesquisas qualitativas em saúde: contribuições teóricas. Cadernos de Saúde Pública, Rio de Janeiro, v. 24, n.1, p. 17-27, jan. 2008. 
ROOS, Maria da Glória Munhoz. Alegria de uma docência. 2014. Dissertação (Mestrado em Educação) Universidade de Santa Cruz do Sul, Santa Cruz do Sul, 2014.

SILVA, Miriã Z:; TOMASEL, Soraia. Socialização e desejos: a docência terapêutica em dois atos. In: FABRIS, ELÍ T. H.; DALIGNA, Maria C.; SILVA, Roberto R. D. (Org.). Modos de ser docente no Brasil contemporâneo: articulações entre pesquisa e formação. São Leopoldo, RS: OIKOS, 2018. p. 108-125.

TARDIF, M. Saberes docentes e formação profissional. 9 ed. Petrópolis, RJ: Vozes, 2008. 